\title{
The Merits of Goal Support as a Self-Control Strategy
}

\author{
Nielsen, Kristian S.; Bauer, Jan Michael
}

Document Version

Accepted author manuscript

Published in:

Social Psychological and Personality Science

DOI:

$10.1177 / 1948550618780729$

Publication date:

2019

License

Unspecified

Citation for published version (APA):

Nielsen, K. S., \& Bauer, J. M. (2019). The Merits of Goal Support as a Self-Control Strategy. Social

Psychological and Personality Science, 10(5), 671-680. https://doi.org/10.1177/1948550618780729

Link to publication in CBS Research Portal

\section{General rights}

Copyright and moral rights for the publications made accessible in the public portal are retained by the authors and/or other copyright owners and it is a condition of accessing publications that users recognise and abide by the legal requirements associated with these rights.

Take down policy

If you believe that this document breaches copyright please contact us (research.lib@cbs.dk) providing details, and we will remove access to the work immediately and investigate your claim. 


\section{The Merits of Goal Support as a Self-Control Strategy Kristian S. Nielsen and Jan Michael Bauer}

Journal article (Accepted manuscript*)

\section{Please cite this article as:}

Nielsen, K. S., \& Bauer, J. M. (2019). The Merits of Goal Support as a Self-Control Strategy. Social

Psychological and Personality Science, 10(5), 671-680. 001: 10.1177/1948550618780729

DOl: https://doi.org/10.1177/1948550618780729

Copyright (C) The Author(s) 2018. Reprinted by permission of SAGE Publications.

* This version of the article has been accepted for publication and undergone full peer review but has not been through the copyediting, typesetting, pagination and proofreading process, which may lead to differences between this version and the publisher's final version AKA Version of Record. 


\title{
Running Head: THE MERITS OF GOAL SUPPORT
}

\section{The Merits of Goal Support as a Self-Control Strategy}

\author{
Kristian Steensen Nielsen and Jan Michael Bauer
}

Copenhagen Business School

This manuscript has been accepted for publication in Social Psychological and Personality Science. Please note that some changes may occur during the copy-editing process, such that the final published version may differ somewhat from this version.

Corresponding author: Kristian Steensen Nielsen, ksn.msc@cbs.dk

Acknowledgements: We gratefully acknowledge the financial support of the Mistra Future Fashion project phase II under the Swedish Mistra Foundation. We thank Denise de Ridder for her helpful comments on earlier drafts of this manuscript, Wencke Gwozdz and Tina Müller for their help with data collection, and Maja Dueholm for her help preparing the manuscript for publication. 


\section{Abstract}

In the present study, we investigated the influence of the presence of others and goal support on the performance of goal-directed behavior across different levels of self-control. Our analysis included survey data from 3,972 respondents across four countries. The results of the analysis revealed four important findings. First, high goal support increased the performance of goal-directed behavior when in the presence of others during decision-making. Second, self-control had a positive effect on goaldirected behavior only when individuals by themselves. Third, while the effect of goal support significantly increased goal-directed behavior independent of self-control ability, people with low self-control reaped the most benefits from having goal support. Finally, we observed that although people with low self-control gained the most benefits from goal support they were also less likely to be positioned in goal-supportive environments.

\section{Keywords}

goal support, self-control, goal-directed behavior, environmentally friendly clothing consumption, four-country survey 
Self-control represents the capability of advancing long-term goals over proximal desires when the two directly conflict (Fujita, 2011; Hofmann \& Vohs, 2016). High self-control has been associated with a wealth of positive outcomes including enhanced academic achievement, better mental health, and subjective well-being (Boals et al., 2011; De Ridder et al., 2012; Hofmann et al., 2014; Tangney et al., 2004). Low self-control has been negatively linked to compulsive buying and financial debt (Achtziger et al, 2015). Positive outcomes associated with high self-control have traditionally been ascribed high self-control individuals' competent resistance and inhibition of goal-conflicting desires. Other researchers have challenged this point of view by suggesting that self-control encompasses other behavioral strategies than resistance and inhibition (e.g., Fujita, 2011). This research has found that strategies such as forming goal-consistent habits (Adriaanse et al., 2014; de Ridder et al., 2012, Galla \& Duckworth, 2015), proactive avoidance of tempting situations (Ent et al., 2015, Hofmann et al., 2012; Milyavskaya \& Inzlicht, 2017), and reappraising tempting objects or situations (Duckworth et al., 2016) similarly (or possibly better) reflect high self-control individuals. Nonetheless, these selfcontrol strategies predominantly focus on internal regulation processes. Recent research suggests that individuals with high self-control also regulate their social environments (vanDellen et al., 2015). Social regulation allows them to utilize external resources that may hold a supportive function in their own self-control efforts. To what extent individuals benefit from situational goal support across different levels of self-control has, however, not previously been studied. To explore this notion, we investigate whether the presence of goal-supportive others can increase goal-directed behavior and evaluate its merits as an effective self-control strategy. Importantly, we assess this goal support strategy against decisions made in the absence of goal support (i.e., being alone) and at different levels of goal support when others are present. Our results reveal a positive, yet heterogeneous effect of goal-supportive others that depends on the individual's level of self-control.

\section{Self-Control and Goal Support}

Pursuing long-term goals is a complicated endeavor entailing the performance of multiple goal- 
directed behaviors over time and in diverse decision-environments. The performance of goal-directed behaviors may be frequently challenged by a large variety of temptations and hindrances capable of undermining goal progress unless self-control is exerted. Many factors influence the emergence of temptations and the exertion of self-control (Hofmann et al., 2012), but a new wave of research has specifically highlighted the significance of interpersonal processes for goal pursuit and self-control (e.g., Fitzsimons \& Finkel, 2011; Righetti \& Kumashiro, 2012; vanDellen et al., 2015). Other people can support the pursuit of personal goals by providing feedback and assisting in the monitoring of behavior (Ashford et al., 2003, Fishbach \& Trope, 2005), both potentially serving as important information sources to facilitate conflict identification and the exertion of self-control (Carver \& Scheier, 1998; Myrseth \& Fishbach, 2009). Pursuing goals in the presence of people may, however, also have a counteractive effect. For instance, other people can inspire indulgence by acting as enactment models of behaviors that are conflicting with personal goals (Dzhogleva \& Lamberton, 2014; Hofmann et al., 2012).

An interesting question that has received limited attention in self-control research is how goal support from others influences behavioral enactment. More specifically, can the presence of goalsupportive others in moments of decision-making positively affect the performance of goal-directed behavior? Previous research indicates that goal support benefits people in their goal pursuit (Brunstein et al., 1996; Feeney, 2004; Righetti \& Kumashiro, 2012). Goal support may benefit goal pursuit in at least two ways. First, supportive others can help ensure that temptations are not elicited (e.g., by restricting exposure to tempting environments), and second, they can remind people of their important goals when temptations have emerged. The latter may occur either implicitly (e.g., the supportive person acts as a role model) or explicitly (e.g., by vocally reminding the person). But not everyone is able to provide effective goal support for the different types of goals that are pursued (Righetti \& Kumashiro, 2012). People should therefore thoughtfully consider the ways in which other people's goal support might be helpful. Fitzsimons \& Shah (2008) found that people categorize others based on their instrumentality for goal pursuits. This process involves approaching goal-facilitating others 
and avoiding goal-obstructing others. The more people select the company of others based on their potential impact on goal pursuits, the more likely they are to succeed (Fitzsimons \& Shah, 2008). The preference for goal-supportive environments was recently linked to self-control ability. Over a series of experiments, VanDellen et al. (2015) observed that individuals with high self-control showed a stronger preference for goal-supportive environments compared to individuals with low self-control. Combined, these results suggest that goal support may be beneficial for goal pursuit and self-control.

\section{Present Study}

In this study, we explored the effect of goal support on the performance of goal-directed behavior across self-control levels. We also investigated how the presence or absence of others in moments of decision-making influenced the performance of goal-directed behavior. This is an important addition to the studies of vanDellen et al. (2015), wherein respondents only were presented with the option of choosing between others with either low or high self-control and not the option of acting alone. In our investigation of goal-directed behavior, self-control, and goal support, we formulated the following hypotheses: (i) high goal support increases goal-directed behavior; (ii) high self-control increases the performance of goal-directed behavior; and (iii) individuals with high self-control are more likely to be accompanied by goal-supportive others.

The hypotheses were examined in the context of clothing consumption with people pursuing a goal to acquire environmentally friendly clothing. Clothing consumption is an interesting domain to explore both self-control and goal support. First, the clothing industry is renowned for its extensive marketing efforts attempting to create purchasing desires in consumers. The industry is similarly recognized for its heavy impact on the environment (Roos, Sandin, Zamani, Peters, \& Svanström, 2016). People pursuing a goal to reduce the environmental impacts of their clothing consumption are, as a result, particularly relevant subjects for research in self-control. This is especially due to the widespread presence of clothing advertisements (e.g., in magazines, on the streets, online, or in shopping malls) and the limited availability of environmentally friendly alternatives, which coupled 
together suggest a heightened likelihood of experiencing goal-conflicting desires. Second, clothing is highly interrelated with social processes. Not only does clothing represent a means of personal communication to others, but the purchase of clothing also frequently happens in the company of other people.

Previous empirical studies exploring the influence of goal support on self-control have mainly relied on one-country (usually the United States) and/or college samples (e.g., Righetti \& Kumashiro, 2012; vanDellen et al., 2015). The present study sought to complement and advance this research by employing another methodological approach to test our hypotheses. Here, we present findings from a large-scale survey undertaken in four countries.

\section{Method}

The data used in this study was collected as part of a larger survey assessing environmentally friendly clothing consumption. The survey included various measurements of consumer behavior and psychological constructs relating to the consumption of clothing with a particular environmental focus. Data was collected in Germany, Poland, Sweden, and the United States using an online survey. Due to its broad inclusion of measurements, the survey was divided in two parts, which were completed with a two- to four-week interval. All the below reported materials, except self-control, were included in the first survey part.

\section{Data Collection}

The data collection took place between October 2016 and January 2017, which was administered by Qualtrics through their panel service. All respondents received an incentive for taking part in the study in the form of points that could be redeemed for different products (e.g., gift cards). The questionnaire was developed in English and subsequently translated into German, Polish and Swedish by qualified translators certified with ISO17100. Translations were proofread by native speakers and all ambiguities were settled in collaboration with the translators before implementing the survey 
online. Numerous quality measures were implemented in both survey parts to maximize data quality and to screen out careless responses (DeSimone et al., 2015; Meade \& Craig, 2011). Among those measures were attention filters including instructed items (e.g., "Please select strongly agree"), bogus items (e.g., "I always sleep less than one hour per night"), measures for answering in patterns (i.e., straight-lining), and self-reported data on answer quality (e.g., "In your honest opinion, should we use your data in our analysis of this study"). Participants failing instructed items were filtered out automatically and participants failing multiple quality checks were replaced (see appendix A for detailed information).

\section{Measures}

Goal Intention. Respondents rated the statement "I intend to acquire mainly environmentally friendly clothing" on a likert scale from 1 (strongly disagree) to 7 (strongly agree). The word "mainly" was included in the phrasing to more accurately reflect the contextual reality of environmentally friendly clothing consumption with environmentally friendly alternatives not always being available (see supplemental materials for completely overview of all measurement items).

Self-Efficacy. Previous research indicates that the effect of social support (a closely related construct to goal support) ${ }^{1}$ is mediated by self-efficacy (Anderson et al., 2006; Bandura, 1997). To exclude the possibility of a confounding effect of self-efficacy, we included a one-item measure of self-efficacy derived from Galla and Duckworth (2015). Respondents rated the statement "I am confident that the next time I want to acquire clothes, I can do it environmentally friendly“ on a likert scale from 1 (strongly disagree) to 7 (strongly agree).

Environmental Clothing Consumption. To assess environmental clothing consumption (ECC), we used the Environmental Apparel Consumption scale by Kim \& Damhorst (1998). The scale consists of a mean score based on eight items to measure the environmental friendliness of clothing consumption $(\alpha=0.836)$. All eight items were measured on a 5 -point likert scale $(1=$ very rarely or never; 5 = very often or always) with the following introductory text: "When acquiring clothing items, 
I..." Example items include "buy clothes with environmentally friendly labeling or packaging techniques," "avoid clothes products because of environmental concerns," and "buy clothing made from organically grown natural fibers."

Presence of Others and Goal Support. Before answering the goal support question, respondents reported whether there were other people present during the "last 5 shopping experiences". The respondents reporting having been accompanied by others at least once during their last five shopping experience were asked an additional goal support question: "In case other people were present during your shopping experiences, were they generally supportive of your goal of acquiring environmentally friendly clothing?" The goal support measure was rated on a 7-point likert scale from 1 (not at all) to 7 (very much) with 'neutral' as the mid-point. This scaling implies that values below 4 could indicate goal hindrance, whereas values above 4 clearly reflect goal support.

Self-Control. To measure self-control, we used the well-validated Brief Self-Control Scale (Tangney et al., 2004) consisting of 13 items $(\alpha=0.845)$. Participants rated their general self-control tendencies on a 7 -point likert scale $(1=$ not at all to $7=$ very much). Example items include "I am good at resisting temptation," "People would say that I have iron self-discipline," and "I am able to work effectively toward long-term goals."

\section{Sample}

The target group for the survey was individuals aged between 18 and 65 years and the sample for survey part I was representative of the population with regard to age, gender, region and education $(\mathrm{N}=10,363)$, which was achieved by resembling the proportions of the population. But as participants themselves decided whether or not to return for part II, subjecting the process to a self-selection bias, we did not achieve full representativeness. The final sample consisted of respondents participating in both survey part I and part II resulting in a total sample of $\mathrm{N}=4,591$ (see Appendix B for sample and country overview). The total re-contact rate for survey part II was $44.3 \%$ and by country: Germany 
(48.2\%), Poland (44.4\%), Sweden (50.7\%), and United States (36.4\%).

For this analysis, we restricted our sample in two ways. First, because the question about goal support was conditional on having a goal to acquire environmentally friendly clothing, we excluded respondents who indicated that they did not have a personal goal to live environmentally friendly ( $\mathrm{N}$ =427). This exclusion decision was made a prior through a filter embedded in the survey structure. The goal to live environmentally friendly was indicated among seven other life goals derived from the 'Aspirations Index' (Kasser \& Ryan, 1996) with one item representing each aspiration category. Second, we excluded respondents with incomplete responses $(\mathrm{N}=192)$. The resulting sample for our analysis consisted of 3,972 respondents.

\section{Analysis Strategy}

Our dataset contained samples from four different countries and therefore required an exploration of its nested structure. Accounting for such a low number of higher level units is generally problematic (Cameron \& Miller, 2015), making the benefits of a multilevel modeling (MLM) approach unclear (e.g. Gorard, 2007). For data with very few clusters like ours, a recent simulation study highlighted the benefits of using a single-level regression and including cluster affiliation as a fixed effect, particularly whenever no second-level variables are of interest (McNeish \& Stapleton, 2016). We used this modelling technique as our main specification and provide the results from different comparative multilevel approaches in Online Supplemental Material. Overall, we observed little differences between the models.

We estimated the association between environmental clothing consumption, self-control and goal support. For the regression, we created z-scores of goal intention, goal support, self-control, and selfefficacy to allow for an easier interpretation of the coefficients. This is particularly helpful to interpret interaction effects, as a z-score of 0 reflects a meaningful and interpretable value. Following Enders and Tofighi (2007), we standardized all variables on the country-level. Results remained qualitatively similar to the uncentered case (results available upon request). To control for potential differences in 
socio-demographic characteristics that were predictive of our dependent variable, we added the following covariates to our regression analysis: age, gender, income, marital status, employment, and country. An unconditional analysis without covariate adjustment is provided in supplemental materials (Table S3).

\section{Results}

The descriptive statistics displayed in Table 1 show a summary of the variables used in our analysis. The full sample was equally composed of the four countries with slightly more female participants and an average age of 42 . The next two columns highlight the descriptive statistics based on the two main groups of interest: the 836 respondents shopping alone and the 3,136 respondents shopping in the company of others. The sample split based on the presence of others underlines the need for the use of covariates in our analysis as characteristics differ significantly between the two groups. Respondents shopping alone reported lower income levels and were more likely to be unmarried. This subsample also consisted of more respondents from Germany and reported lower levels of environmental clothing consumption despite an insignificant difference in the level of goal intention. Goal support from other people present during shopping was on average "neutral" (scale mid-point). 
Table 1. Descriptive statistics

\begin{tabular}{lccccc}
\hline Variable & Full sample & Shopping alone & Shopping in company & Min & Max \\
\hline ECC & 2.76 & 2.71 & $2.78^{*}$ & 1 & 5 \\
Self-control & 4.45 & 4.53 & $4.44^{*}$ & 1 & 7 \\
Goal support & - & - & 4.00 & 1 & 7 \\
Goal intention & 4.38 & 4.25 & 4.42 & 1 & 7 \\
Self-efficacy & 4.23 & 4.17 & $4.24^{*}$ & 1 & 7 \\
Age (years) & 42.37 & 46.51 & $41.26^{*}$ & 18 & 65 \\
Female (\%) & 58 & 57 & 59 & 0 & 1 \\
Income (category) & 4.64 & 4.43 & $4.70^{*}$ & 1 & 11 \\
Married/living together (\%) & 59 & 41 & $64 *$ & 0 & 1 \\
Full-time (\%) & 54 & 53 & 54 & 0 & 1 \\
Part-time (\%) & 11 & 13 & 11 & 0 & 1 \\
Germany (\%) & 43 & $21^{*}$ & 0 & 1 \\
Poland (\%) & 26 & 18 & $27^{*}$ & 0 & 1 \\
Sweden (\%) & 25 & 19 & $26^{*}$ & 0 & 1 \\
United States (\%) & 24 & 20 & $26^{*}$ & 0 & 1 \\
\hline N & 25 & 336 & 3,136 & & \\
\hline
\end{tabular}

Note: Test for significant differences on the 5\% level compared to shopping alone. Income is measured in country-specific ranked categories (see Gwozdz, Nielsen, \& Müller, 2017 for further details).

\section{Goal Support and Goal-Directed Behavior}

Table 2 provides the regression results from our main analysis. The relationship between ECC and the main variables of interest is shown in Model 1. To test the impact of having other people present on the performance of goal-directed behavior, we regressed ECC on presence of others with people shopping alone as the reference category. Compared to this reference, people shopping in the presence of others showed a small but significantly higher performance of ECC. In order to test the influence of goal support, we next looked only at the people who shopped in the company of others (Model 2). Here, we found that the performance of ECC increased with rising levels of goal support. As expected, the goal intention itself had a significant and positive relationship with ECC. Despite holding goal intention constant during our main analysis, the positive interaction effect between goal intention and goal support shows that the effect of goal support increased with goal intention (Model 3). Selfefficacy was significant throughout all our models. Nonetheless, goal support remained statistically 
significant showing that goal support had a distinct relationship with ECC beyond self-efficacy. Comparing these OLS estimates with the MLM (see supplemental material Table S4 and S5), we observed two minor but noteworthy differences: first, the interaction term between goal intention and goal support (Model 3) was estimated less precise and p-values of 0.06 slightly exceeded the usual level of significance. Second, the interaction term in Model 4 was estimated more precisely using different MLMs, which increased our confidence in the main results that are discussed in the next section.

Table 2. Regression results

\begin{tabular}{|c|c|c|c|c|c|c|}
\hline & Model 1 & Model 2 & Model 3 & Model 4 & Model 5 & Model 6 \\
\hline Variable & $\mathrm{ECC}$ & ECC & ECC & $\mathrm{ECC}$ & $\begin{array}{l}\text { Presence of } \\
\text { others } \\
\text { (yes/no) }\end{array}$ & $\begin{array}{c}\text { Goal } \\
\text { support }\end{array}$ \\
\hline $\begin{array}{l}\text { Presence of others (yes) } \\
\text { Presence of others x } \\
\text { self-control (z-score) }\end{array}$ & $\begin{array}{c}0.06^{*} \\
{[0.01,0.10]}\end{array}$ & & & $\begin{array}{c}0.06^{*} \\
{[0.01,0.10]} \\
-0.06^{*} \\
{[-0.10,-0.01]}\end{array}$ & & \\
\hline $\begin{array}{l}\text { Goal support (z-score) } \\
\text { Goal intention x goal } \\
\text { support (z-scores) }\end{array}$ & & $\begin{array}{c}0.16^{* * *} \\
{[0.14,0.18]}\end{array}$ & $\begin{array}{c}0.16^{* * *} \\
{[0.13,0.18]} \\
0.04 * * * \\
{[0.02,0.06]}\end{array}$ & & & \\
\hline Goal intention (z-score) & $\begin{array}{c}0.41 * * * \\
{[0.38,0.43]}\end{array}$ & $\begin{array}{c}0.35 * * * \\
{[0.32,0.38]}\end{array}$ & $\begin{array}{c}0.36 * * * \\
{[0.33,0.39]}\end{array}$ & $\begin{array}{c}0.41 * * * \\
{[0.39,0.44]}\end{array}$ & $\begin{array}{c}-0.00 \\
{[-0.02,0.01]}\end{array}$ & $\begin{array}{c}0.62 * * * \\
{[0.55,0.69]}\end{array}$ \\
\hline $\begin{array}{l}\text { Self-control (z-score) } \\
\text { Self-efficacy (z-score) }\end{array}$ & $\begin{array}{c}0.00 \\
{[-0.02,0.02]} \\
0.15^{* * *} \\
{[0.12,0.17]}\end{array}$ & $\begin{array}{c}-0.03^{*} \\
{[-0.05,-0.01]} \\
0.13^{* * *} \\
{[0.10,0.15]}\end{array}$ & $\begin{array}{c}-0.03 * * \\
{[-0.05,-0.01]} \\
0.12 * * * \\
{[0.10,0.15]}\end{array}$ & $\begin{array}{c}0.04 * \\
{[0.00,0.08]} \\
0.15^{* * *} \\
{[0.12,0.17]}\end{array}$ & $\begin{array}{c}-0.00 \\
{[-0.02,0.01]} \\
0.02 * * \\
{[0.01,0.04]}\end{array}$ & $\begin{array}{c}0.13 * * * \\
{[0.07,0.18]} \\
0.26 * * * \\
{[0.18,0.33]}\end{array}$ \\
\hline $\begin{array}{l}N \\
\text { adj. } R^{2}\end{array}$ & $\begin{array}{l}3972 \\
0.47\end{array}$ & $\begin{array}{l}3136 \\
0.51\end{array}$ & $\begin{array}{l}3136 \\
0.51\end{array}$ & $\begin{array}{l}3972 \\
0.48\end{array}$ & $\begin{array}{l}3972 \\
0.10\end{array}$ & $\begin{array}{l}3136 \\
0.32\end{array}$ \\
\hline
\end{tabular}

Note: All regressions estimated via ordinal least squares (OLS) include the additional covariates: age, sex, income, marital status, full-time \& part-time employment, and a set of country dummies. Confidence intervals on a $95 \%$ level are in brackets. ${ }^{*} \mathrm{p}<0.05,{ }^{* *} \mathrm{p}<0.01,{ }^{* * *} \mathrm{p}<0.001$. The complete regression table and an analysis without covariates are provided in Online Supplemental Materials Table S2 and S3 respectively.

\section{Self-Control and Goal-Directed Behavior}

As evidenced by Model 1, we did not observe a significant relationship between self-control and ECC at a given level of goal intention. But a more detailed look into this relationship reveals that the impact 
of self-control differs between people shopping alone or in the presence of others. To more effectively carve out the precise influence of self-control, we had to consider the relationship between goal support and goal-directed behavior. Model 4 highlights the heterogeneous relationship between selfcontrol and the presence of others. Introducing an interaction term showed a positive and significant relation between self-control and ECC for people shopping alone. However, this was not observed for people shopping in the presence of others where ECC did not increase with higher levels of selfcontrol. Even though the relationship was negative, the difference was not statistically significant (beta: -0.01: CI $[-0.04,0.01])$. This effect was smaller compared to the coefficients in Model 2 and Model 3 (this sample only included people with others present), which could be attributed to the indirect effect of self-control on ECC through goal support (see discussion below). Goal support was, however, not included in Model 4.

These findings highlight that looking at the overall results (Model 1) overshadows important heterogeneity between shopping alone or with others. This heterogeneity is best highlighted by Figure 1, showing an interaction effect between the presence of others and self-control (based on Model 4). While people with low self-control clearly benefited from having other people present, this was not true for people with high self-control (+2 SD of the mean). There was no significant difference between going alone or with others for people with high self-control $(F(1,3957)=1.16, p=0.28)$.

The comparison between going alone and in company of others was based on the average level of goal support, thus neglecting differences in the actual level of support. Figure 2 allows a closer look into this second level of heterogeneity. The bar charts display the difference in predicted ECC scores between people going alone versus people with different levels of goal support, a relation sensitive to the actual level of self-control. These estimates were based on a set of dummy variables for each level of goal support (range 1 to 7 ) with shopping alone as reference and an interaction with selfcontrol (numerical results and significance tests between groups are presented in the supplemental material S4 and S5). The upper graph presents the results for a low level of self-control (-2 SD). For these people, the point estimates suggest a positive impact on ECC for virtually any value of the goal 
support scale with a significant positive difference for people with "neutral" goal support indicated by the numerical value 4 in Figure 2. There was no statistical difference between going alone or with "neutral" goal support for people with average self-control (middle graph), which reflects the inverse relationship of self-control across the two groups. By contrast, "neutral" goal support had a significantly negative effect on ECC for people with high self-control (+2 SD) compared to going alone. People with high self-control showed a comparably high level of ECC when going alone and therefore only benefited from the presence of others when the accompanying people were highly goal-supportive.

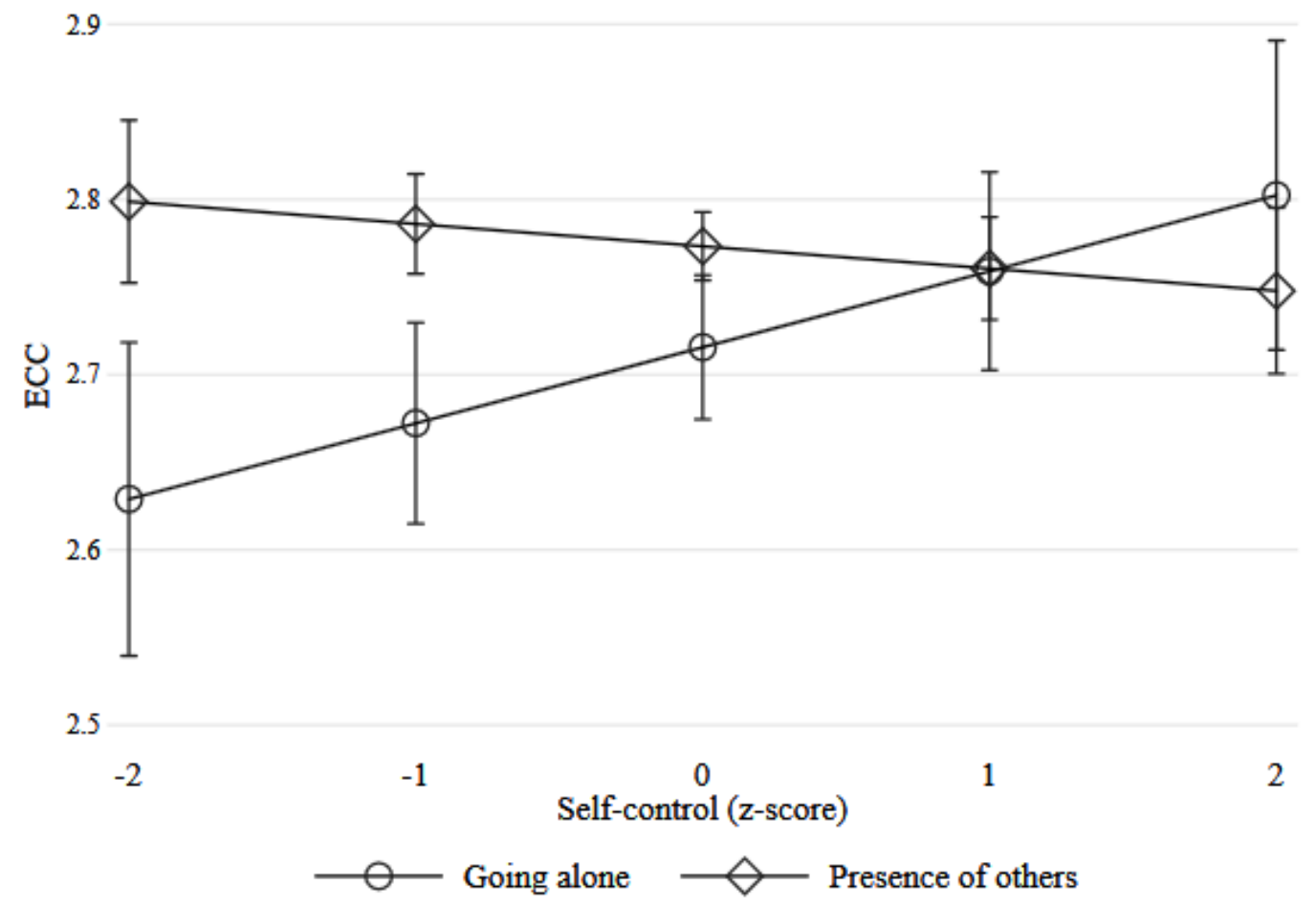

Figure 1. The marginal effects of self-control interacted with presence of others. Predicted ECC is based on Model 4 in Table 2. Bars indicate the 95\% confidence intervals. 


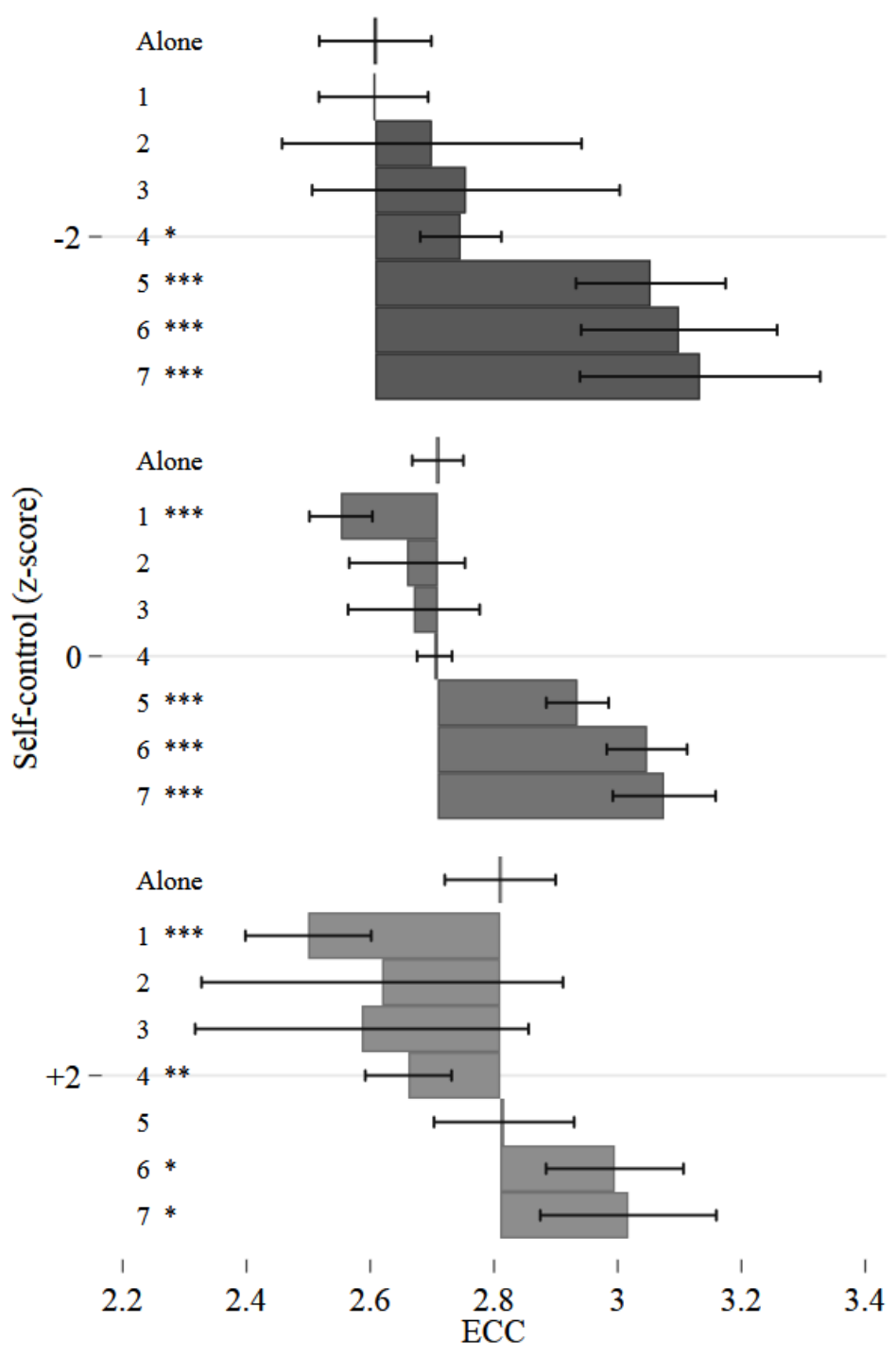

Figure 2. Bars indicate the marginal differences in predicted ECC compared to people going alone for different levels of self-control. Subscale indicates people with other people present at different levels of goal support ranging from 1 to $7(1=$ not at all, $4=$ neutral, $7=$ very much $)$. Error bars indicate the $95 \%$ confidence intervals and significant differences compared to alone are indicated by $* \mathrm{p}<0.05, * * \mathrm{p}<0.01, * * * \mathrm{p}<0.001$. Complete regression results and predictions are presented in the supplemental material S6 and S7.

\section{Who Brings Goal Support?}

Hypothesis 3 builds on the work by vanDellen et. al (2015) suggesting that people with high selfcontrol purposefully select themselves into goal-supportive environments in order to achieve their goals. This cross-sectional study cannot claim to identify a clear causal relationship but demonstrates that people with similar goal intentions show different (self-reported) behavior, which depends on the interplay between self-control and goal support. To shed more light on the question of what actually 
determines whether someone goes shopping alone, we regressed a binary variable concerning the presence of others (1) or not (0) on self-control and included the usual covariates variables (Model 5, Table 2). The results showed that self-control did not predict the probability of being alone or with others during shopping in our main analysis. ${ }^{2}$ But importantly, when people were accompanied by others, people with higher self-control were more likely to be accompanied by highly goal-supportive others (Model 6).

\section{Discussion}

Social processes have recently gained increasing prominence in self-control research. The present study sought to contribute to this research by investigating the effectiveness of using goal support from others as a self-control strategy in the pursuit of an environmental clothing goal. Our analyses support that the strategy of bringing goal-supportive others has merits as a self-control strategy. We formulated three hypotheses relating to goal-directed behavior, self-control, and goal support. Our first hypothesis stated that the presence of highly goal-supportive others would increase goal-directed behavior. This hypothesis was strongly supported. The company of goal-supportive others can assist individuals in monitoring behavior and act as a reminder to self about one's goals. Previous research has found similar results in that supportive others can help bolster self-control (Brunstein et al., 1996; Righetti \& Kumashiro, 2012; Rusbult et al., 2009). By contrast, we suspect that the company of others who are not goal-supportive may cause people to more frequently resist the enactment of goalconsistent desires and instead perform goal-conflicting behaviors (see also Hofmann et al., 2012). While this result clearly indicates a positive effect of high goal support on goal-directed behavior, we should entertain the possibility that the mere presence of others had a systematic effect on goaldirected behavior (Lou, 2005; Zajonic, 1965). Empirically disentangling a mere presence effect from the effect of social influences (e.g., goal support) exerted by others present is, however, challenging. But Figure 2 suggests that accompanying others with a "neutral" level of support—assumed to most closely resemble a mere presence-do not have a consistent effect on behavior compared to going 
alone. The effect of "neutral" support varied significantly with the level of self-control. Unless the accompanying others differed systematically in some unobserved characteristic, these findings are hard to align with the existence of strong effect of the mere presence of others.

Our second hypothesis posited that having high self-control would increase the performance of goal-directed behavior. We did not find a statistically significant main effect of self-control, which contradicts most previous findings (e.g., de Ridder et al., 2012). However, subsequent analyses revealed a heterogeneous interplay between self-control, presence of others, and goal support. To our surprise, the expected effect of self-control on the performance of goal-directed behavior was limited to people shopping alone. In contrast, self-control had a slightly negative effect on the performance of goal-directed behavior when other people were present (independent of goal support level). This finding is rather surprising and we can only speculate on possible explanations for this pattern. One explanation could be that individuals with high self-control instead balance their goal pursuit (e.g. Carver \& Scheier, 1981; Higgins, 1996; Hofmann et al., 2014). This would imply that other important goals may be similarly prioritized such as financial or appearance goals. Future research should validate and explore this potential self-control dynamic in greater detail.

The heterogeneous effect of self-control with regards to goal support has important implications for the effectiveness of goal support itself as a self-control strategy. People with high self-control only benefitted from goal support (compared to going alone) when the accompanying others were highly supportive of their goal, high self-control individuals should be particularly sensitive towards goal supportiveness when deciding whether or not to bring other people shopping. Similar care is not required for people with lower levels of self-control, who benefit from virtually any positively valenced level of goal support. In general, the effect of bringing high goal support was strongest for people with low self-control, which suggests that goal support might be a particularly effective selfcontrol strategy for these people.

The third hypothesis concerned who were more likely to bring goal-supportive others. We did not observe any differences across self-control ability in whether people preferred going alone or with 
others in our main analysis. But when people were accompanied by others, self-control did have an effect on how supportive these people were. We predicted that high self-control individuals would be most likely to bring goal-supportive others. Our analysis supported this hypothesis with high selfcontrol individuals more often positioning themselves in supportive environments than low selfcontrol individuals. High self-control individuals were also less likely to bring low-supportive others. These results are in line with the findings of VanDellen et al. (2015) and insinuate the importance of goal instrumentality in the accompanying people (Fitzsimons \& Shah, 2008).

\section{Limitations}

The present study has several noteworthy limitations. The primary limitations are the reliance on selfreported behavior to assess the effectiveness of self-control and goal support as well as the use of single-item measurements for goal support, self-efficacy, and goal intention without any known psychometric properties. This issue also translates into a remaining uncertainty about potential differences in those psychometric properties across the four countries. Single-item measurements make it impossible to fully assess potential measurement invariance for our models (Putnick \& Bornstein, 2016; Steenkamp \& Baumgartner, 1998). A related issue associated with a four-country sample is the difficulty in perfectly accounting for the nested structure of the data. However, as the intra-cluster correlation (ICC) for our dependent variable shows to be very small and results remain robust across different estimation techniques, we expect any exiting bias to be small.

Another limitation is the inability to determine the exact role played by goal-supportive others based on the collected data as well as ascribe the origin of goal support to any specific group of people (e.g., friends, partners, or family). Although we find that people with self-control are more likely to be accompanied by highly supportive others, we do not know whether this reflects an active selection from their social network or whether it reflects a higher availability of goal support within their social network. We also cannot entirely disentangle the true effect of (situational) goal support from general goal supportiveness. For instance, a person could be accompanied by others that are unsupportive of 
the environmental goal but who are otherwise supportive of that person's goals. Similarly, a person could be accompanied by others who are supportive of the environmental goal, although they are generally unsupportive of the person's goals. Future experimental studies are encouraged to control for the general goal-supportiveness of accompanying others in the process of explicating the exact function and effect of goal support. Finally, we merely explored goal support as a self-control strategy within one behavioral domain, thus future research should seek to broaden the scope by incorporating other domains.

\section{Conclusion}

Taken together, the present study supports the merits of bringing goal support as an effective selfcontrol strategy. This is especially true for individuals with low self-control. Our findings also suggest that individual differences in self-control are important for the effectiveness of goal support on the performance of goal-directed behavior. Our study, thus, joins recent studies in highlighting the importance of external environments for self-control success. While self-control did not have a direct effect on the presence of others, it did influence the goal-supportiveness of the accompanying people. 


\section{References}

Achtziger, A., Hubert, M., Kenning, P., Raab, G., \& Reisch, L. (2015). Debt out of control: The links between self-control, compulsive buying, and real debts. Journal of Economic Psychology, 49, 141-149.

Adriaanse, M. A., Kroese, F. M., Gillebaart, M., \& De Ridder, D. T. (2014). Effortless inhibition: Habit mediates the relation between self-control and unhealthy snack consumption. Frontiers in Psychology, 5, 444.

Anderson, E. S., Wojcik, J. R., Winett, R. A., \& Williams, D. M. (2006). Social-cognitive determinants of physical activity: The influence of social support, self-efficacy, outcome expectations, and self-regulation among participants in a church-based health promotion study. Health Psychology, 25, 510 -520.

Ashford, S. J., Blatt, R., \& Walle, D. V. (2003). Reflections on the looking glass: A review of research on feedback-seeking behavior in organizations. Journal of Management, 29, 773-799.

Bandura, A. (1997). Self-efficacy: The exercise of control. New York: W H. Freeman.

Boals, A., vanDellen, M. R., \& Banks, J. B. (2011). The relationship between self-control and health: The mediating effect of avoidant coping. Psychology \& Health, 26(8), 1049-1062.

Brunstein, J. C., Dangelmayer, G., \& Schultheiss, O. C. (1996). Personal goals and social support in close relationships: Effects on relationship mood and marital satisfaction. Journal of Personality and Social Psychology, 71(5), 1006-1019.

Cameron, R. C., \& Miller, D. L. (2015). A Practitioner's Guide to Cluster-Robust Inference. Journal of Human Resources, 50(2), 317-372

Carver, C. S., \& Scheier, M. F. (1981). The self-attention-induced feedback loop and social facilitation. Journal of Experimental Social Psychology, 17(6), 545-568.

Carver, C. S., \& Scheier, M. F. (1998). On the self-regulation of behavior. New York: Cambridge University Press 
DeSimone, J.A., Harms, P.D., \& DeSimone, A.J. (2015). Best practice recommendations for data screening, Management Department Faculty Publications, Paper 124.

De Ridder, D. T., Lensvelt-Mulders, G., Finkenauer, C., Stok, F. M., \& Baumeister, R. F. (2012). Taking stock of self-control: a meta-analysis of how trait self-control relates to a wide range of behaviors. Personality and Social Psychology Review, 16(1), 76-99.

Duckworth, A. L., Gendler, T. S., \& Gross, J. J. (2016). Situational strategies for selfcontrol. Perspectives on Psychological Science, 11(1), 35-55.

Dzhogleva, H., \& Lamberton, C. P. (2014). Should birds of a feather flock together? Understanding self-control decisions in dyads. Journal of Consumer Research, 41(2), 361-380.

Enders, C. K., \& Tofighi, D. (2007). Centering Predictor Variables in Cross-Sectional Multilevel Models: A New Look at an Old Issue. Psychological Methods, 12(2), 121-138.

Ent, M. R., Baumeister, R. F., \& Tice, D. M. (2015). Trait self-control and the avoidance of temptation. Personality and Individual Differences, 74, 12-15.

Feeney, B. C. (2004). A secure base: Responsive support of goal strivings and exploration in adult intimate relationships. Journal of Personality and Social Psychology, 87, 631-648.

Fishbach, A., \& Trope, Y. (2005). The substitutability of external control and self-control. Journal of Experimental Social Psychology, 41(3), 256-270.

Fitzsimons, G. M., \& Finkel, E. J. (2011). Outsourcing self-regulation. Psychological Science, 22(3), 369-375.

Fitzsimons, G. M., \& Shah, J. Y. (2008). How goal instrumentality shapes relationship evaluations. Journal of Personality and Social Psychology, 95(2), 319-337.

Fujita, K. (2011). On conceptualizing self-control as more than the effortful inhibition of impulses. Personality and Social Psychology Review, 15(4), 352-366.

Galla, B. M., \& Duckworth, A. L. (2015). More than resisting temptation: Beneficial habits mediate the relationship between self-control and positive life outcomes. Journal of Personality and Social Psychology, 109(3), 508-525. 
Gorard, S. (2007). The dubious benefits of multi-level modeling. International Journal of Research and Method in Education, 30(2), 221-236.

Gwozdz, W., Nielsen, K. S., \& Müller, T. (2017). An Environmental Perspective on Clothing Consumption: Consumer Segments and Their Behavioral Patterns. Sustainability, 9(5), 762.

Higgins, E. T. (1996). The "self digest": Self-knowledge serving self-regulatory functions. Journal of Personality and Social Psychology, 71, 1062-1083.

Hofmann, W., \& Vohs, K. D. (2016). Desire and self-regulation. In K. D. Vohs, \& R. F. Baumeister (Eds.), Handbook of Self-Regulation: Research, Theory, and Applications (3rd ed., pp. 76-94), New York, NY: Guilford Press.

Hofmann, W., Baumeister, R. F., Förster, G., \& Vohs, K. D. (2012). Everyday temptations: an experience sampling study of desire, conflict, and self-control. Journal of Personality and Social Psychology, 102(6), 1318-1335.

Hofmann, W., Luhmann, M., Fisher, R. R., Vohs, K. D., \& Baumeister, R. F. (2014). Yes, but are they happy? Effects of trait self-control on affective well-being and life satisfaction. Journal of Personality, 82(4), 265-277.

Kasser, T., \& Ryan, R. M. (1996). Further examining the American dream: Differential correlates of intrinsic and extrinsic goals. Personality and Social Psychology Bulletin, 22, 280-287.

Kim, H.S., \& Damhorst, M.L. (1998). Environmental Concern and Apparel Consumption. Clothing and Textiles Research journal, 16(3),126-133.

Luo, X. (2005). How does shopping with others influence impulsive purchasing? Journal of Consumer psychology, 15(4), 288-294.

McNeish, D., \& Stapleton, L. M. (2016). Modeling Clustered Data with Very Few Clusters. Multivariate Behavioral Research, 51(4), 495-518.

Meade, A.W. \& Craig, S.B. (2011). Identifying careless responses in survey data. Paper presented at the 26th Annual Meeting of the Society for Industrial and Organizational Psychology, Chicago, IL. 
Milyavskaya, M., \& Inzlicht, M. (2017). What's So Great About Self-Control? Examining the Importance of Effortful Self-Control and Temptation in Predicting Real-Life Depletion and Goal Attainment. Social Psychological and Personality Science, 1948550616679237.

Myrseth, K. O. R., \& Fishbach, A. (2009). Self-control: A function of knowing when and how to exercise restraint. Current Directions in Psychological Science, 18(4), 247-252.

Putnick, D. L., \& Bornstein, M. H. (2016). Measurement invariance conventions and reporting: the state of the art and future directions for psychological research. Developmental Review, 41, 7190.

Righetti, F., \& Kumashiro, M. (2012). Interpersonal goal support in achieving ideals and oughts: The role of dispositional regulatory focus. Personality and Individual Differences, 53(5), 650654.

Roos, S., Sandin, G., Zamani, B., Peters, G., \& Svanström, M. (2016). Will Clothing Be Sustainable? Clarifying Sustainable Fashion. In Muthu, S. S. (Eds.), Textiles and Clothing Sustainability (pp. 1-45). Springer Singapore.

Rusbult, C. E., Finkel, E. J., \& Kumashiro, M. (2009). The michelangelo phenomenon. Current Directions in Psychological Science, 18(6), 305-309.

Steenkamp, J. B. E., \& Baumgartner, H. (1998). Assessing measurement invariance in crossnational consumer research. Journal of Consumer Research, 25(1), 78-90.

Tangney, J. P., Baumeister, R. F., \& Boone, A. L. (2004). High self-control predicts good adjustment, less pathology, better grades, and interpersonal success. Journal of Personality, 72(2), 271-324.

Uchino, B. N. (2006). Social support and health: a review of physiological processes potentially underlying links to disease outcomes. Journal of Behavioral Medicine, 29(4), 377-387.

VanDellen, M., Shah, J. Y., Leander, N. P., Delose, J. E., \& Bornstein, J. X. (2015). In Good Company Managing Interpersonal Resources That Support Self-Regulation. Personality and Social Psychology Bulletin, 41(6), 869-882. 
Zajonc, R. B. (1965). Social facilitation. Science, 149(3681), 269-274. 


\section{Notes}

1. While goal support conceptually resembles social support, we see the two constructs as being distinct in at least one important way. Social support is typically defined to include both the structure of person's social life (e.g., group membership) and more explicit functions such as emotional support (Uchino, 2006). Although social support can be goal-specific (Brunstein et al., 1996), it refers to received or perceived support occurring across time and situations. Our conceptualization of goal support, by contrast, strictly refers to support for a particular goal in a specific situation.

2. Similar results are obtained from using a logit model presented in Table S8. 


\section{Appendix A}

\begin{tabular}{|c|c|}
\hline Criteria & Number of Respondents Disqualified \\
\hline $\begin{array}{l}\text { 1. Failing two or more quality checks } \\
\begin{array}{l}\text { - Please select very much like me } \\
\text { (if like me or very much like me is not } \\
\text { selected) } \\
\text { - I put enough effort towards this study } \\
\text { (if disagree or strongly disagree is } \\
\text { selected) } \\
\text { - I gave this study enough attention } \\
\text { (if disagree or strongly disagree is } \\
\text { selected) } \\
\text { - In your honest opinion, should we use } \\
\text { your data in our analysis in this study? } \\
\text { (if no is selected) }\end{array}\end{array}$ & $\mathrm{N}=345$ \\
\hline 2. More than $10 \%$ missing values & $\mathrm{N}=25$ \\
\hline $\begin{array}{l}\text { 3. Answering in patterns } \\
\text { - Answering the highest category for all } \\
\text { items in a scale; or } \\
\text { - Participants that are in the first variance } \\
\text { percentile for all three variables that are } \\
\text { expected to vary significantly: life } \\
\text { goals, goal commitment, and values. }\end{array}$ & $\mathrm{N}=187$ \\
\hline $\begin{array}{l}\text { 4. Straight-lining } \\
\text { - All respondents that clicked the same } \\
\text { answer category for all of the goal } \\
\text { commitment items }\end{array}$ & $\mathrm{N}=1,141$ \\
\hline
\end{tabular}

Note: the measurements of life goals, goal commitment, and values are not included in this manuscript. 
Appendix B

\section{Survey Part I}

\begin{tabular}{lcc} 
Total $N$ & 10,363 & 4,591 \\
Germany & 2,427 & 1,170 \\
Poland & 2,485 & 1,105 \\
Sweden & 2,316 & 1,176 \\
United States & 3,135 & 1,140 \\
\hline
\end{tabular}

\section{Final Sample}
4,591
1,176
1,140 